\title{
Descripción Histológica del Aparato Reproductor de Avestruz Hembra (Strutio camelus var. domesticus)
}

\author{
Histological Description of the Ostrich Female Reproductive System (Strutio camelus var. \\ domesticus)
}

Julio Illanes ${ }^{1}$; Francisco Matus²; Víctor Leyton ${ }^{1}$; Felipe Venegas²; Bárbara Fertilio ${ }^{1}$ \& Mario Castro $^{1}$

ILLANES, J.; MATUS, F.; LEYTON, V.; VENEGAS, F.; FERTILIO, B. \& CASTRO, M. Descripción histológica del aparato reproductor de avestruz hembra (Strutio camelus var. Domesticus). Int. J. Morphol., 36(4):1252-1261, 2018.

RESUMEN: El auge de la producción intensiva del avestruz, comenzó en la década de los noventa impulsada por la calidad de su carne y potencialidad de sus subproductos. La raza empleada para producción por la calidad nutricional y sabor de su carne es el híbrido llamado African black (Struthio camelus var. domesticus). En cuanto a la reproducción, el avestruz hembra alcanza su madurez sexual a partir de los 2,5 años. Es importante considerar el aparato genital en aves de producción, ya que una alteración en él, puede generar deficiencias en la fertilidad que se traducen en un menor número de crías. El estudio histológico del aparato reproductor de la hembra será una herramienta más que permitirá resolver problemas reproductivos. Para este análisis se obtuvo muestras de los diferentes segmentos del aparato reproductor de 6 avestruces hembras en edad reproductiva y se procesaron de acuerdo a las técnicas histológicas de rutina. Los cortes fueron observados, fotografiados y analizados bajo microscopio de luz. Obtenidas las fotografías, se analizó comparativamente su morfología con la descrita en la gallina (Gallus gallus). El aparato reproductor de la hembra tiene la particularidad de tener desarrollado solo el ovario y oviducto izquierdo. El ovario es de gran tamaño y en forma de racimo, el cual varía según la estacionalidad. Presenta folículos primordiales, previtelogénicos, vitelogénicos y atrésicos. Los folículos vitelogénicos presentan células de la granulosa y de la teca interna y externa. El oviducto presenta de cefálico a caudal los siguientes segmentos: infundíbulo, magnum, istmo, útero y vagina, que desemboca en la cloaca a nivel del urodeo. En ellos hay pliegues de variada longitud, grosor y número que comprometen la mucosa y submucosa, con glándulas de secreción mucosa y serosa a excepción de la vagina. El análisis histológico comparativo, permitió establecer que la morfología del aparato reproductor de la hembra es semejante a la observada en la gallina con ciertas diferencias microscópicas (Gallus gallus).

PALABRAS CLAVE: Avestruz; Histología; Aparato reproductor femenino.

\section{INTRODUCCIÓN}

El African black conocido científicamente como Struthio camelus var. domesticus es un híbrido entre el Red neck y el Blue neck, avestruz que pasó de ser un ave salvaje proveniente de África a ser un animal de producción para consumo humano. Se prefiere este híbrido por su carne de mayor calidad y mejor sabor. Los machos son de menor tamaño, más fértiles y dóciles lo que facilita su manejo, por lo que es muy apreciado en producción animal (Deeming, 2001). Los órganos reproductores del avestruz hembra son el ovario y oviducto izquierdo que desemboca en el urodeo, siendo el ovario derecho rudimentario (Huchzermeyer, 2000; Deeming). En el avestruz el ovario está suspendido de la pared dorsal del cuerpo, en posición ventral al riñón y dorsomedial al saco aéreo abdominal ipsilateral. La posición, tamaño y forma del ovario dependen de la estacionalidad y varían durante la época de cría (Camiruaga, 2004). El oviducto conduce el ovocito fecundado hasta la cloaca, y en sentido contrario permite que los espermatozoides alcancen el sitio de fecundación (Dyce $e t$ al., 2004). El oviducto de las aves presenta cinco regiones cada una con su función respectiva, estas son infundíbulo, magnum, istmo, útero y vagina (Fudge, 2000). En el infundíbulo se recibe y engloba la yema, y es el sitio donde ocurre la fecundación (Whittow, 2000). En el magnum se secreta la albúmina o clara y es el segmento más largo del oviducto. En el istmo se forman alrededor del huevo las membranas testáceas de la cáscara (Camiruaga). En el útero (o glándula de la cáscara) que es de forma globosa ocurre la calcificación de la cáscara. La vagina en las aves permite el paso del huevo formado desde el útero hacia la cloaca du-

\footnotetext{
${ }^{1}$ Facultad de Medicina, Clínica Alemana Universidad del Desarrollo. Santiago, Chile.

${ }^{2}$ Facultad de Medicina Veterinaria, Universidad Iberoamericana de Ciencias y Tecnología. Santiago, Chile.
} 
rante la postura u oviposición y también tiene importancia en la selección, el transporte y el almacenamiento de los espermatozoides (Hafez, 2002). El avestruz alcanza la madurez sexual al tercer año de vida, pero con manejos nutricionales se puede adelantar al segundo año de vida. El avestruz tiene un periodo de cría estacional de días largos y puede poner hasta 50 huevos por temporada. El tiempo que se demora entre la formación y postura de un huevo es de 48 horas en comparación con la gallina (Gallus gallus) que es de aproximadamente 24 horas (Camiruaga). El conocimiento de su morfología facilitará la comprensión y mejor manejo de los aspectos biológicos, fisiológicos y reproductivos. En el presente trabajo se describe la histología de los distintos segmentos del aparato genital de Struthio camelus var. domesticus y se analiza comparativamente con los resultados descritos en la gallina (Gallus gallus).

\section{MATERIAL Y MÉTODO}

El material biológico empleado en este trabajo, procede de muestras del aparato genital de 6 avestruces hembras adultas, clínicamente sanas, provenientes de criaderos de la Sexta Región de Chile. El material se obtuvo en el Frigorífico "CAREN" ubicado en la Región Metropolitana, Chile. Las muestras de ovario y oviducto (infundíbulo, magnum, istmo, útero y vagina), fueron fijadas en formalina tamponada al $10 \%$ y se continuó con el procedimiento habitual de técnica histológica. Se empleó la técnica corriente de hematoxilina y eosina, y van Gieson, con la finalidad de observar los tejidos muscular y conectivo (Luna, 1968). Cortes histológicos de $5 \mu \mathrm{m}$ de grosor fueron observados, fotografiados y analizados bajo microscopio de luz (Olympus BX41 con cámara digital Olympus C-5060 Wide zoom, 5.1 mega pixel). Con las fotografías se realizó un análisis comparativo de los aspectos histológicos encontrados en avestruz con aquellos descritos en la gallina.

\section{RESULTADOS}

Ovario: los folículos ováricos en distintos estados de maduración se disponen a modo de un racimo. (Figs. 1a,b). La corteza ovárica está recubierta en algunas áreas por epitelio cúbico simple (Fig. 2b), en otras por epitelio prismático simple ciliado (Fig. 2d) y también se encuentra epitelio prismático seudoestratificado. Bajo el epitelio hay una delgada capa de tejido conectivo denso que constituye la albugínea (Figs. 2b,d). En el tejido conectivo laxo del estroma cortical se observan folículos en distintos estados de maduración (Figs. 2a,c), algunos de ellos, los más grandes, hacen prominencia en la superficie. Éstos se clasifican en primordiales, previtelogénicos, vitelogénicos y atrésicos.

En los folículos primordiales el ovocito con núcleo vesiculoso, está rodeado por un epitelio plano o cúbico bajo de células foliculares que corresponden a la capa granulosa. Externamente a la membrana basal se disponen algunos miofibroblastos (Fig. 2e). En los folículos previtelogénicos, el ovocito con núcleo vesiculoso y escaso vitelo está rodeado por una granulosa de epitelio cúbico, una membrana basal muy notoria y externamente a ella una teca indiferenciada vascularizada con miofibroblastos de disposición concéntrica (Fig. 2f). En los folículos vitelogénicos, el ovocito con abundante vitelo está rodeado por una capa granulosa de epitelio cúbico, la teca interna vascularizada y la teca externa con abundantes miofibroblastos de disposición concéntrica (Figs. $2 \mathrm{~g}, \mathrm{~h}$ ). Los folículos atrésicos, que son más pequeños, presentan numerosas vacuolas lipídicas.

Oviducto: es un conducto que presenta cinco segmentos (Fig. 1c):

1. Infundíbulo: corresponde al primer segmento del oviducto que se encuentra adyacente al ovario y presenta una pared delgada con largos y numerosos pliegues. Los pliegues están revestidos por una mucosa conformada por un epitelio prismático seudoestratificado ciliado con células caliciformes y un corion de tejido conectivo denso con abundantes fibras colágenas (Figs. 3a,b). Interpuestas en el epitelio se observan glándulas tubuloalveolares simples (Figs. 3c,d) y alveolares simples (Figs. 3e,f) de secreción mucosa. No se observa submucosa. La muscular de disposición plexiforme, emite fibras musculares lisas que se proyectan por la mucosa de los pliegues. La serosa posee tejido conectivo denso y está rodeada por mesotelio (Figs. 3c,d).

2. Magnum: es el segmento del oviducto de mayor longitud, de mayor diámetro y con numerosos y gruesos pliegues. Los pliegues están revestidos por una mucosa conformada por un epitelio seudoestratificado prismático ciliado con células caliciformes. En el corion se distribuyen abundantes glándulas tubulares ramificadas de secreción serosa. La submucosa está conformada por tejido conectivo laxo muy irrigada y con fibras musculares lisas. La muscular se dispone en una capa circular interna que se proyecta tenuemente por la amplia submucosa de los pliegues y una capa externa de disposición plexiforme. La serosa posee tejido conectivo laxo muy irrigada y está rodeada por mesotelio. (Figs. 4a-d).

3. Istmo: es el segmento del oviducto de menor longitud, de menor diámetro y pared más delgada, con numerosos y tortuosos pliegues. Los pliegues están revestidos por una mu- 

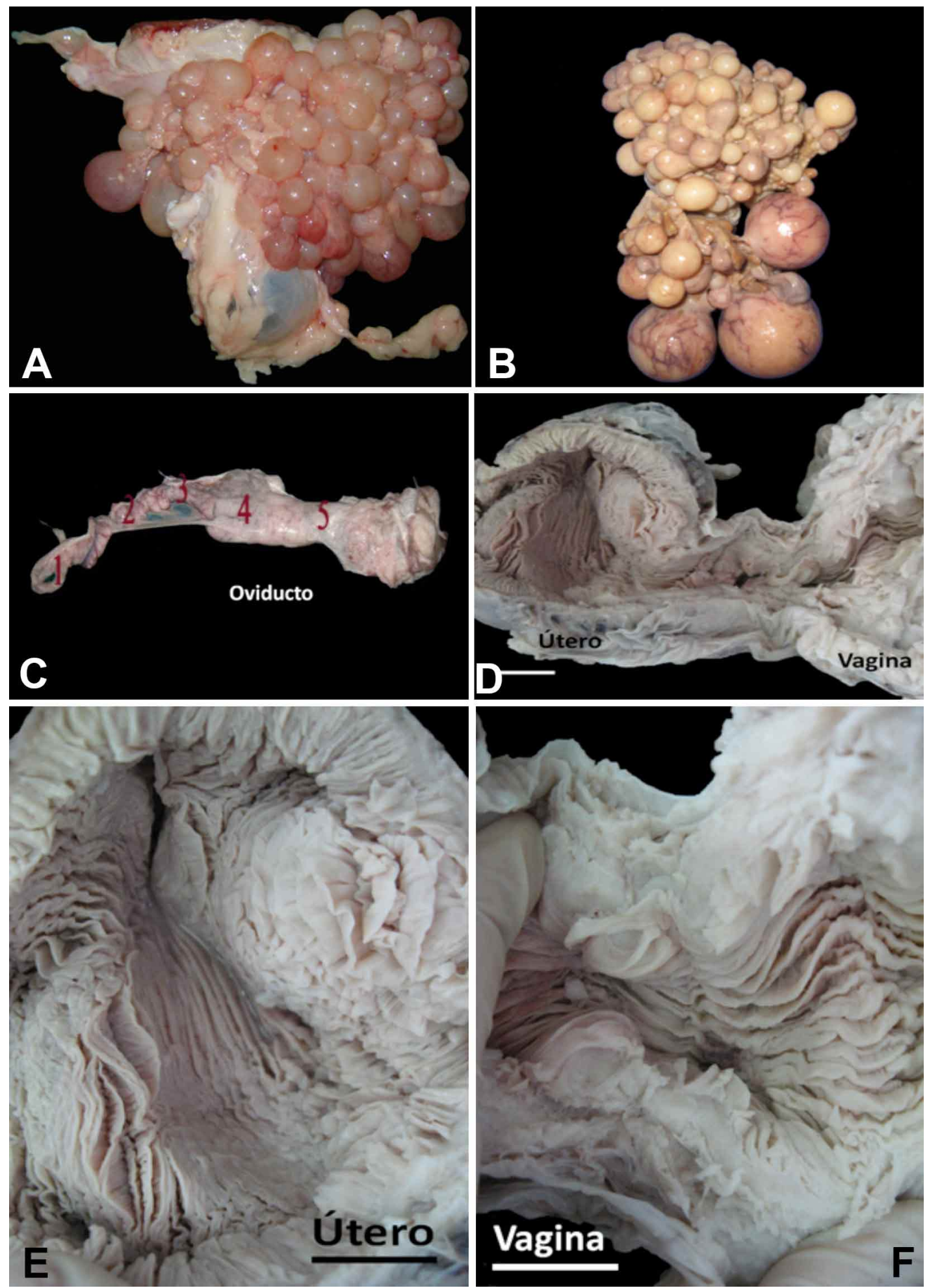

Fig. 1 A. Vista macroscópica de ovario in toto con folículos en distintos estadios de desarrollo dispuestos a modo de racimo. B: Vista macroscópica de ovario in toto fijado en formol que muestra folículos en distintos estadios de desarrollo. C. Vista macroscópica de oviducto in toto mostrando los distintos segmentos. De distal a proximal: 1 infundibulum, 2 magnum, 3 istmo, 4 útero y 5 vagina. D. Vista macroscópica de corte sagital de oviducto unión útero-vagina. Barra $=2,5 \mathrm{~cm}$. E. Vista macroscópica de corte sagital de útero. Barra =2,5 cm. F. Vista macroscópica de corte sagital de vagina. Barra $=2,5 \mathrm{~cm}$. 

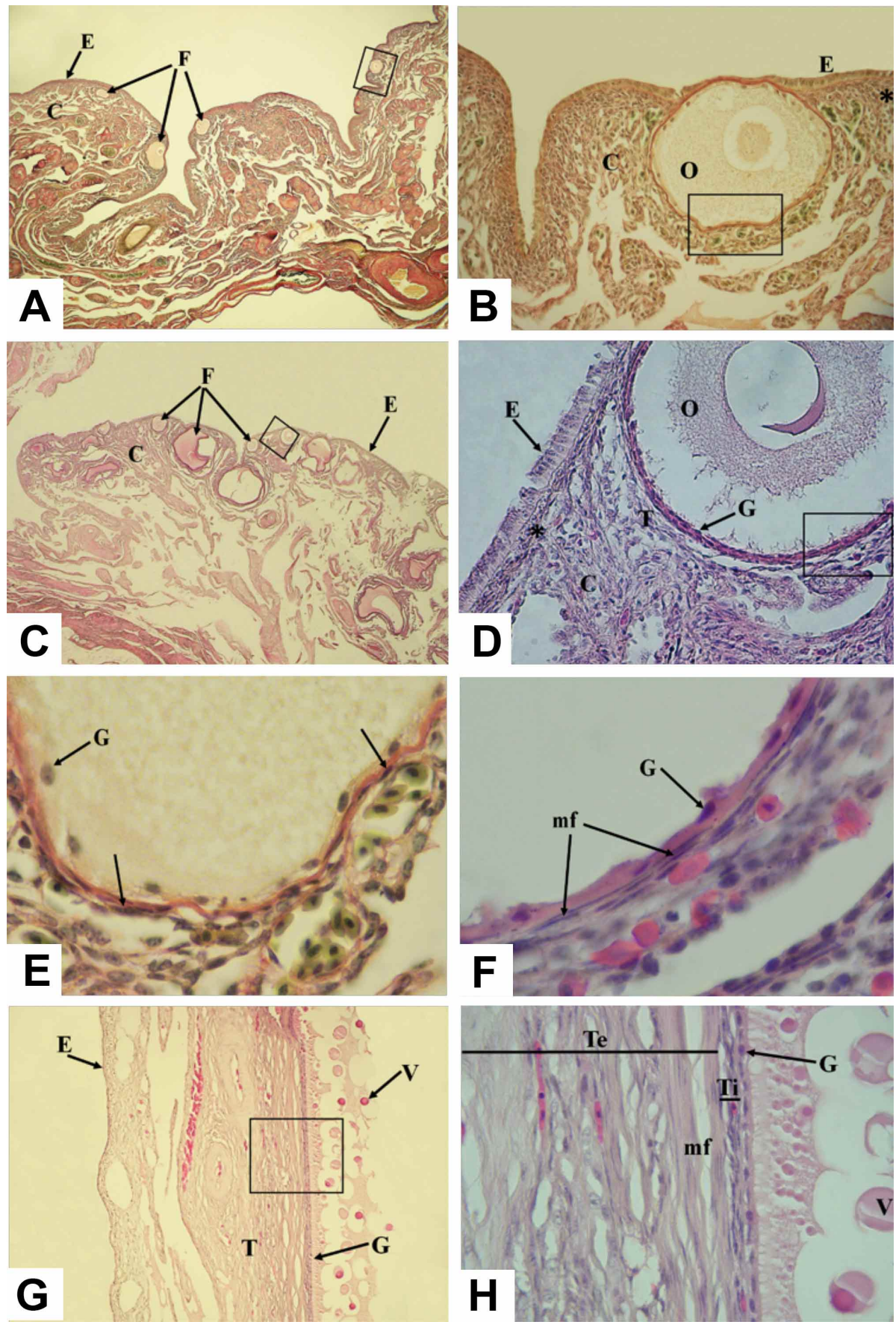

Fig. 2. A. Corte histológico panorámico de ovario. Folículos primordiales y previtelogénicos (F), epitelio ovárico (E), corion de tejido conectivo (C). Tinción: Van Gieson, 12,5X. B. Mayor aumento del recuadro de la Fig. 2a. Epitelio ovárico cúbico simple (E), ovocito de un folículo primordial $(\mathrm{O})$, corion de tejido conectivo (C) y albugínea (*). Tinción: Van Gieson, 400X. C.Corte histológico panorámico de ovario. Folículos primordiales y previtelogénicos (F), epitelio ovárico (E), corion de tejido conectivo (C). Tinción: H-E, 12,5X. D. Mayor aumento del recuadro de la Fig. 2c. Epitelio ovárico prismático simple ciliado (E), ovocito de un folículo previtelogénico (O), corion de tejido conectivo (C), albugínea $(*)$, teca indiferenciada (T) muy vascularizada y granulosa (G). Tinción: H-E, 400X. E. Mayor aumento del recuadro de la Fig. 2b. Las flechas señalan miofibroblastos que rodean la membrana basal de la granulosa $(\mathrm{G})$ de un folículo primordial. Van Gieson, 1000X. F. Mayor aumento del recuadro de la Fig. 2d. Teca indiferenciada muy vascularizada con miofibroblastos ( $\mathrm{mf}$ ) dispuestos concéntricamente rodeando la membrana basal de la granulosa (G) de un folículo previtelogénico. Tinción: H-E, 1000X. G. Corte histológico panorámico de la pared de un folículo vitelogénico. Epitelio ovárico (E), teca (T), granulosa $(\mathrm{G})$ y gotas de vitelo (V). Tinción: H-E, 200X. H. Mayor aumento del recuadro de la Fig. 2g. Teca externa (Te) con miofibroblastos $(\mathrm{mf})$, teca interna $(\mathrm{Ti})$, granulosa $(\mathrm{G})$ y gotas de vitelo $(\mathrm{V})$. Tinción: H-E, 1000X. 

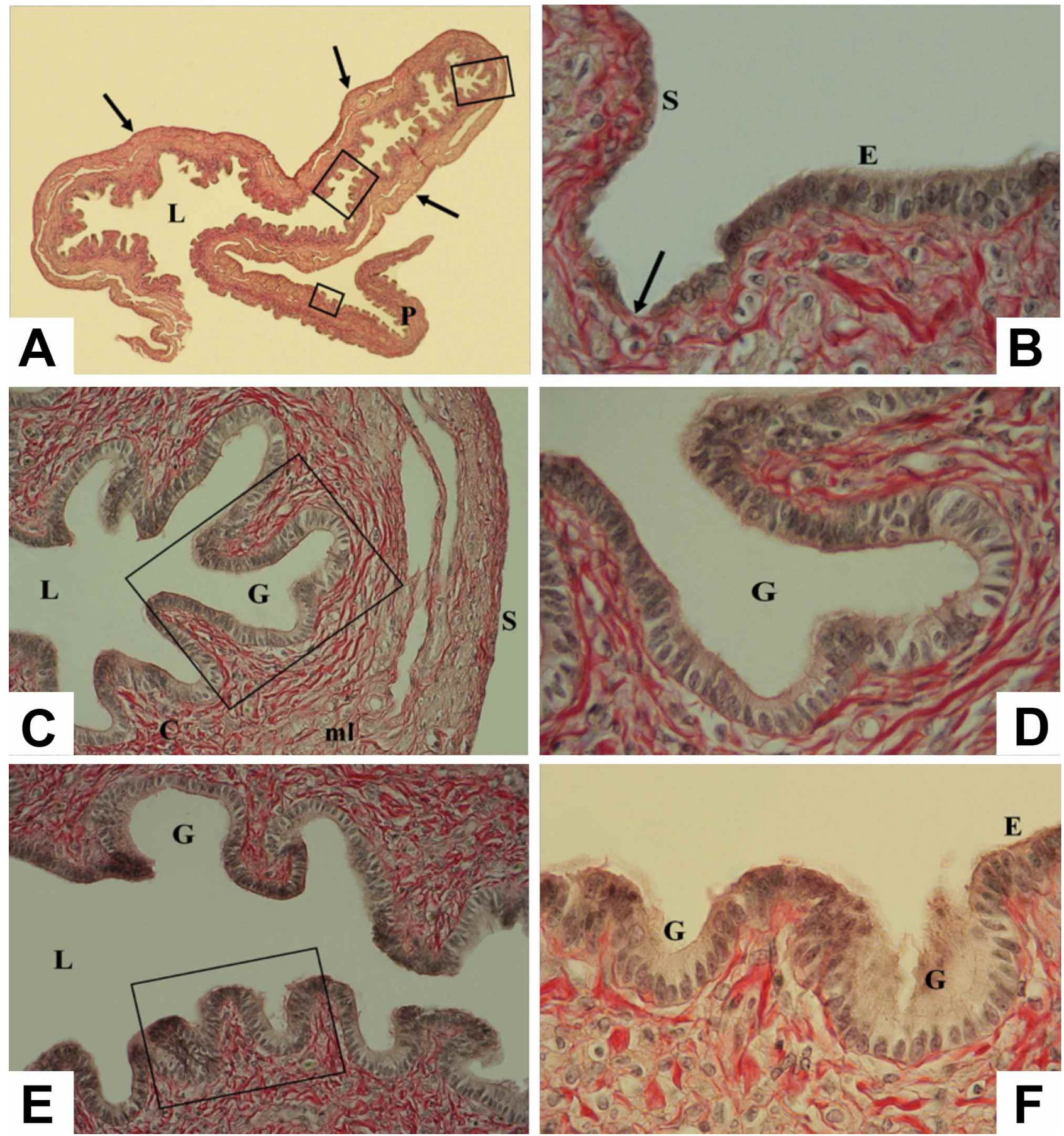

Fig. 3a: Corte histológico panorámico de la pared de infundibulum con numerosos pliegues (P), serosa (flechas) y lumen (L). Tinción: Van Gieson, 12,5X. Fig. 3b: Mayor aumento del recuadro inferior de la Fig. 3a. Transición (flecha) entre la serosa (S) y el epitelio prismático seudoestratificado ciliado con células caliciformes de la mucosa (E). Tinción: Van Gieson, 1000X. Fig. 3c: Mayor aumento del recuadro superior de la Fig. 3a. Glándulas tubuloalveolares simples de secreción mucosa (G), corion de tejido conectivo denso (C), lumen (L), musculatura lisa plexiforme (ml) y serosa (S). Tinción: Van Gieson, 400X. Fig. 3d: Mayor aumento del recuadro de la Fig. 3c. Glándula tubuloalveolar simple de secreción mucosa (G), Tinción: Van Gieson, 1000X. Fig. 3e: Mayor aumento del recuadro del centro de la Fig. 3a. Lumen (L), glándulas alveolares simples de secreción mucosa (G), Tinción: Van Gieson, 400X. Fig. 3f: Mayor aumento del recuadro de la Fig. 3e. Glándulas alveolares simples $(\mathrm{G})$ y epitelio prismático seudoestratificado ciliado con células caliciformes (E) de la mucosa. Tinción: Van Gieson, 1000X. 

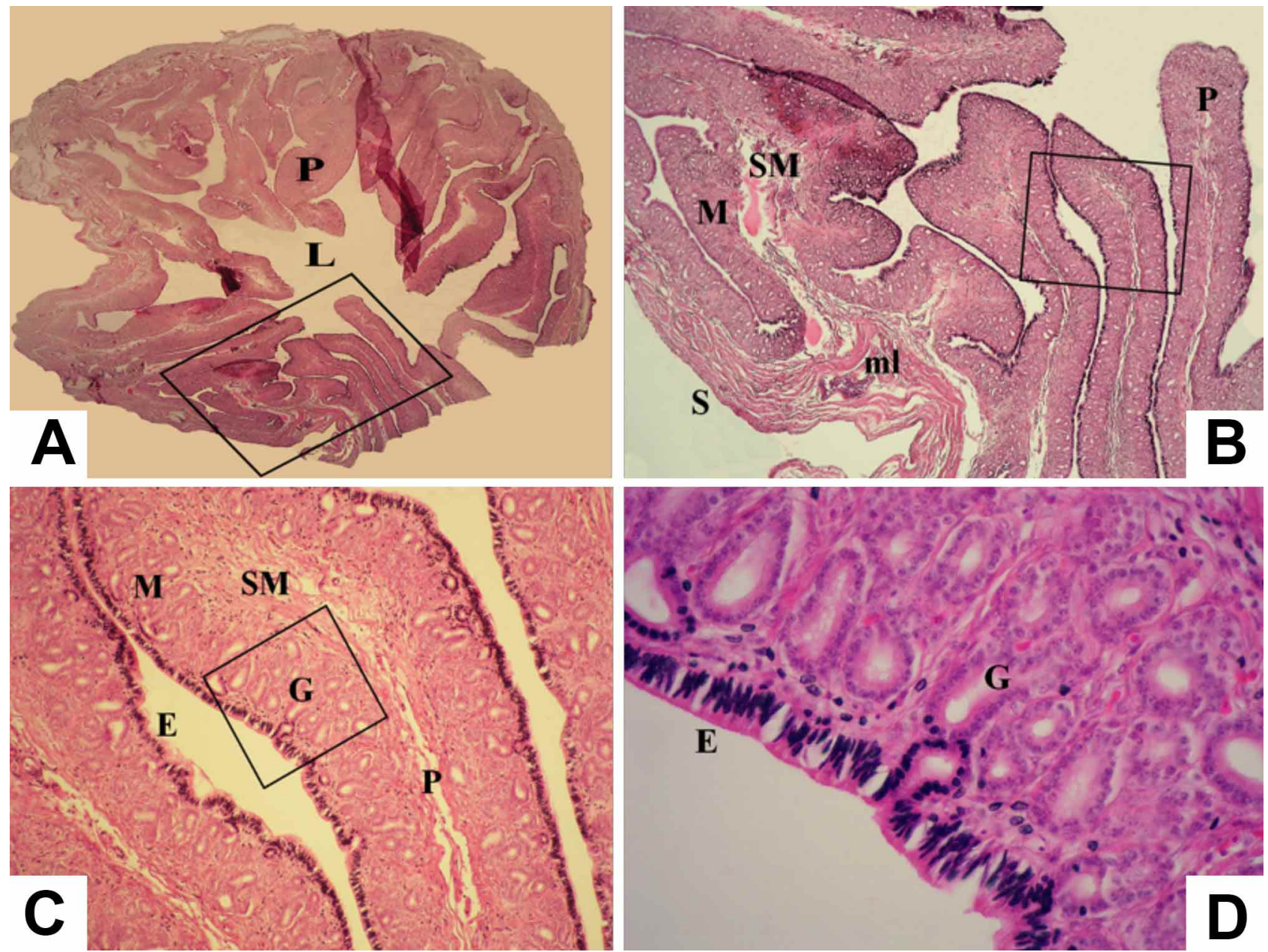

Fig. 4a: Corte histológico panorámico de la pared de magnum con numerosos y gruesos pliegues (P) y su lumen (L). Tinción: H-E, 12,5X. Fig. 4b: Mayor aumento del recuadro de la Fig. 4a. Gruesos pliegues (P), mucosa (M), submucosa (SM), musculatura lisa (ml) de disposición circular interna y plexiforme externa. Serosa (S). Tinción: H-E, 100X. Fig. 4c: Mayor aumento del recuadro de la Fig. 4b. Muestra un pliegue (P), la mucosa (M) con su epitelio (E) y corion de tejido conectivo con glándulas (G) y submucosa (SM). Tinción: HE, 200X. Fig. 4d: Mayor aumento del recuadro de la Fig. 4c. Muestra el epitelio de revestimiento prismático seudoestratificado ciliado con células caliciformes (E) y corion de tejido conectivo con glándulas tubulares ramificadas de secreción serosa (G). Tinción: H-E, 400X.

cosa conformada por un epitelio prismático seudoestratificado ciliado con células caliciformes. El corion presenta abundantes glándulas tubulares simples de secreción serosa (Figs. 5c,d). La submucosa, de tejido conectivo laxo está muy irrigada y con algunas fibras musculares lisas (Figs. 5b,c). La muscular se dispone en una capa circular interna que se proyecta finamente por la submucosa de los pliegues y una capa externa de disposición plexiforme. La serosa posee tejido conectivo laxo muy irrigada y está rodeada por mesotelio (Figs. 5a-d).

4. Útero: presenta una forma globosa con numerosos y largos pliegues (Figs. 1d,e). Los pliegues están revestidos por una mucosa con un epitelio prismático seudoestratificado ciliado con células caliciformes. El corion presenta abundantes glándulas tubulares ramificadas de secreción serosa. La submucosa delgada de tejido conectivo laxo muy irrigada y con algunas fibras musculares lisas. La muscular se dispone en una capa circular interna que emite finas proyecciones hacia la submucosa y una capa externa de disposición plexiforme. La serosa posee tejido conectivo laxo muy irrigada y está rodeada por mesotelio (Figs. 6a-d).

5. Vagina: es un segmento corto y angosto que presenta una pared bien desarrollada con numerosos y largos pliegues (Figs. 1d,f). Los pliegues muy ramificados, con numerosas vellosidades constituyen una densa trama y están revestidos por una mucosa con un epitelio prismático seudoestratificado 

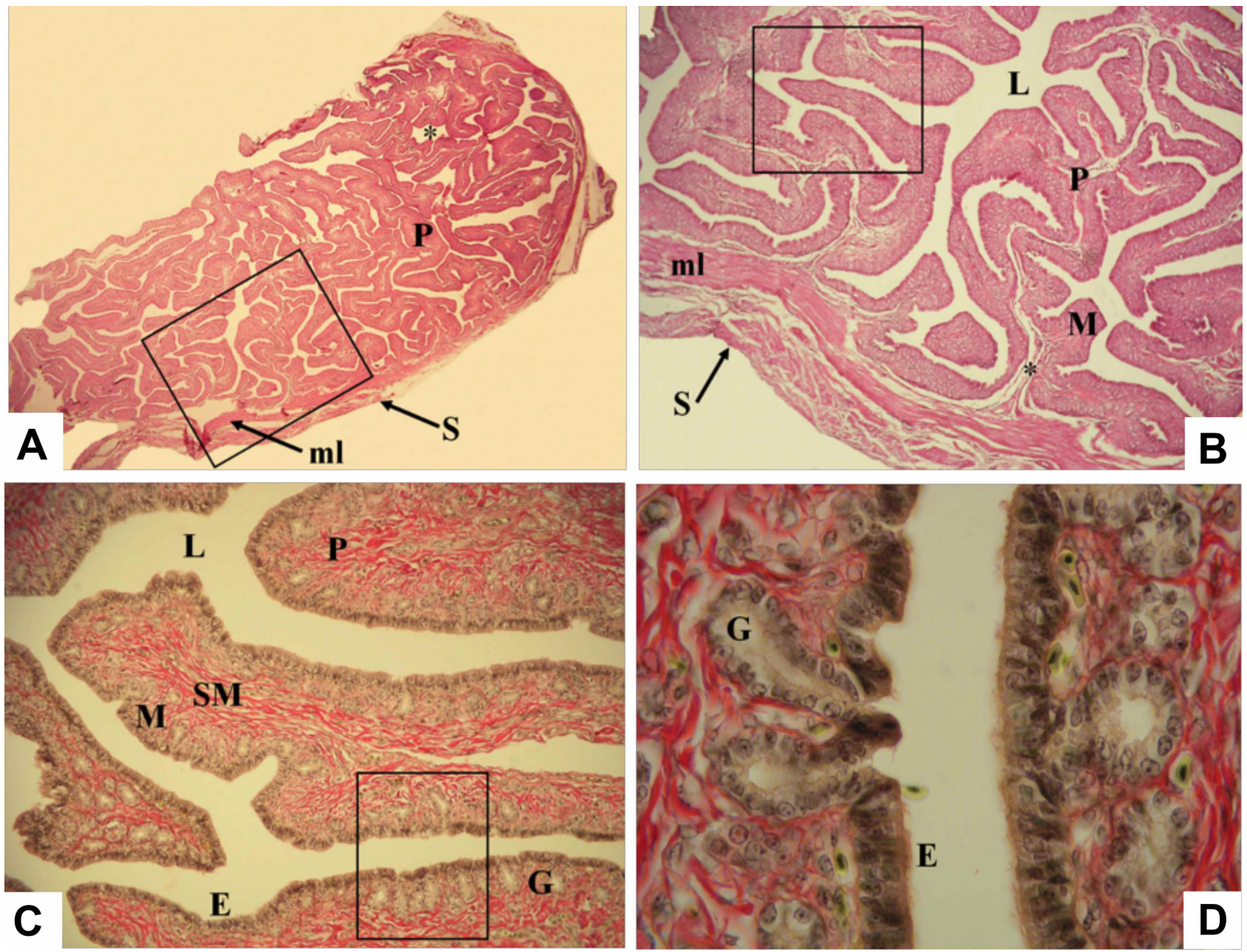

Fig. 5a: Corte histológico panorámico de la pared de istmo con numerosos y tortuosos pliegues (P), lumen (*), serosa (S) y musculatura lisa (ml). Tinción: H-E, 12,5X. Fig. 5b: Mayor aumento del recuadro de la Fig. 5a. Pliegue (P), mucosa (M), submucosa (*), musculatura lisa $(\mathrm{ml})$ de disposición circular interna y plexiforme externa. La primera se proyecta finamente por la submucosa de los pliegues. Serosa (S) y lumen (L). Tinción: H-E, 40X. Fig. 5c: Mayor aumento del recuadro de la Fig. 5b. El pliegue (P) muestra la mucosa (M) con su epitelio (E) y corion de tejido conectivo denso con glándulas (G). Submucosa (SM) y lumen (L). Tinción: Van Gieson, 200X. Fig. 5d: Mayor aumento del recuadro de la Fig. 5c. Mucosa con epitelio de revestimiento prismático seudoestratificado ciliado con células caliciformes (E) y corion de tejido conectivo denso con glándulas tubulares simples de secreción serosa (G). Tinción: Van Gieson, 1000X.

ciliado con células caliciformes. El corion de tejido conectivo denso no presenta glándulas. La disposición de estos pliegues da lugar a la formación de numerosos espacios. La submucosa de tejido conectivo laxo muy irrigada y con manojos de fibras musculares lisas. La muscular se dispone en una gruesa capa circular interna que se proyecta notoriamente por la submucosa de los pliegues y sus ramificaciones, llegando también a las vellosidades y una capa externa de disposición plexiforme (Figs. 7a-f). Presenta una adventicia de tejido conectivo laxo y una serosa que posee tejido conectivo laxo y está rodeada por mesotelio.

\section{DISCUSIÓN}

Comparativamente a nivel macroscópico no se observan mayores diferencias entre el aparato reproductor de la hembra de avestruz (Struthio camelus var. domesticus) y el de la gallina (Gallus gallus). En el avestruz el ovario y oviducto izquierdo se hallan adosados a la pared dorsal del cuerpo y ventral al riñón, semejante a lo que ocurre en la gallina (Sisson \& Grossman, 1999; Whittow; Fudge; Harrison \& Lightfoot, 2005). Tanto en el avestruz como en 

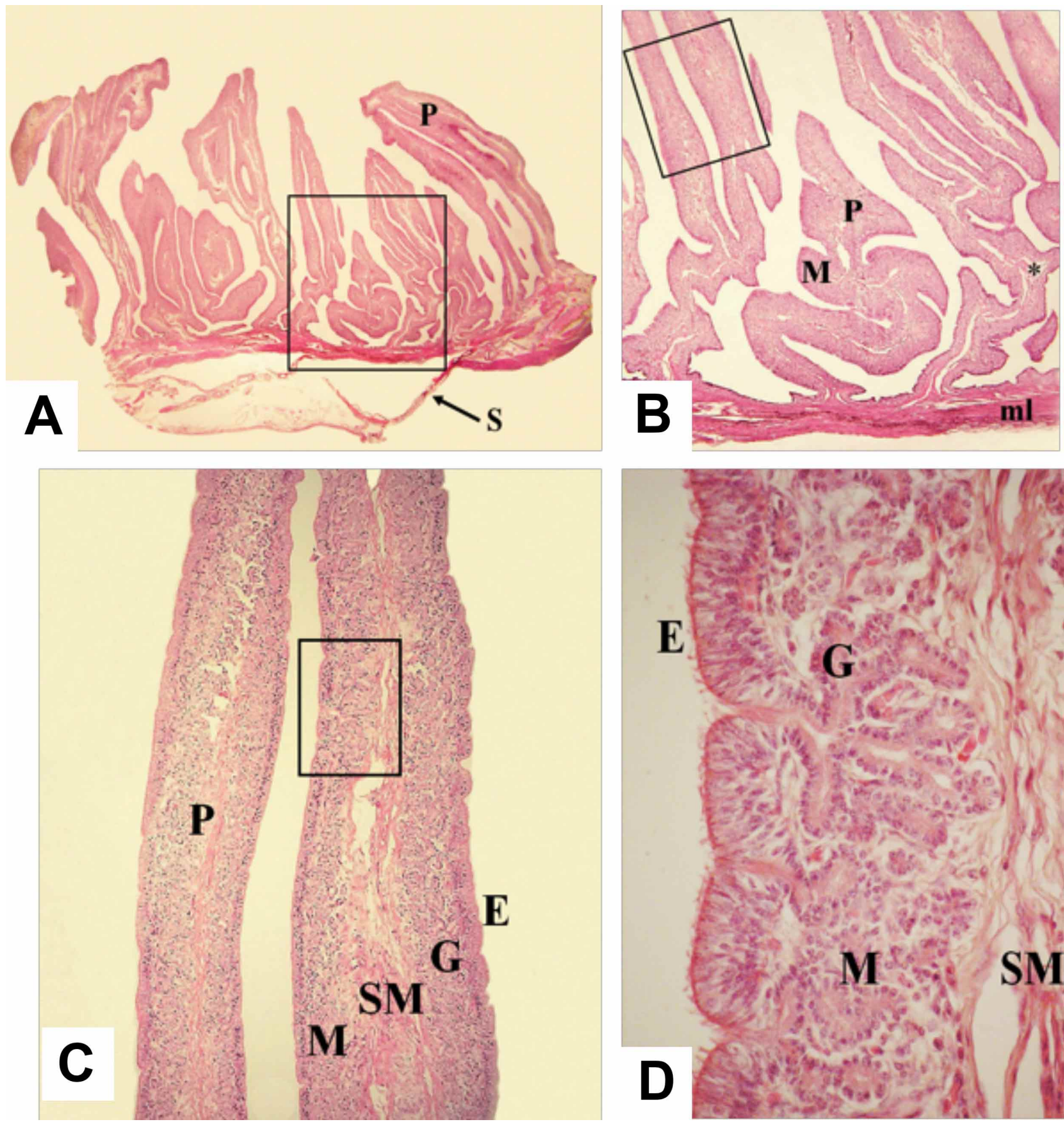

Fig. 6a: Corte histológico panorámico de la pared de útero con largos y numerosos pliegues (P), serosa (S). Tinción: H-E, 12,5X. Fig. 6b: Mayor aumento del recuadro de la Fig. 6a. Pliegue (P), mucosa (M), submucosa $\left.{ }^{*}\right)$, musculatura lisa (ml) de disposición circular interna y plexiforme externa. La primera emite finas proyecciones hacia la submucosa de los pliegues. Tinción: H-E, 40X. Fig. 6c: Mayor aumento del recuadro de la Fig. 6b. El pliegue (P) muestra la mucosa (M) con su epitelio (E) y corion de tejido conectivo con numerosas glándulas (G). Submucosa (SM). Tinción: H-E, 200X. Fig. 6d: Mayor aumento del recuadro de la Fig. 6c. Mucosa (M) con epitelio de revestimiento prismático seudoestratificado ciliado con células caliciformes (E) y corion de tejido conectivo con glándulas tubulares ramificadas de secreción serosa $(\mathrm{G})$. Submucosa (SM). Tinción: H-E, 400X.

la gallina el ovario se observa como un racimo de folículos en diferentes estados de desarrollo, los que varían de acuer- do a la estacionalidad (fotoperiodo) y edad de las aves (Deeming; Camiruaga; Fudge; Whittow; Hafez). 

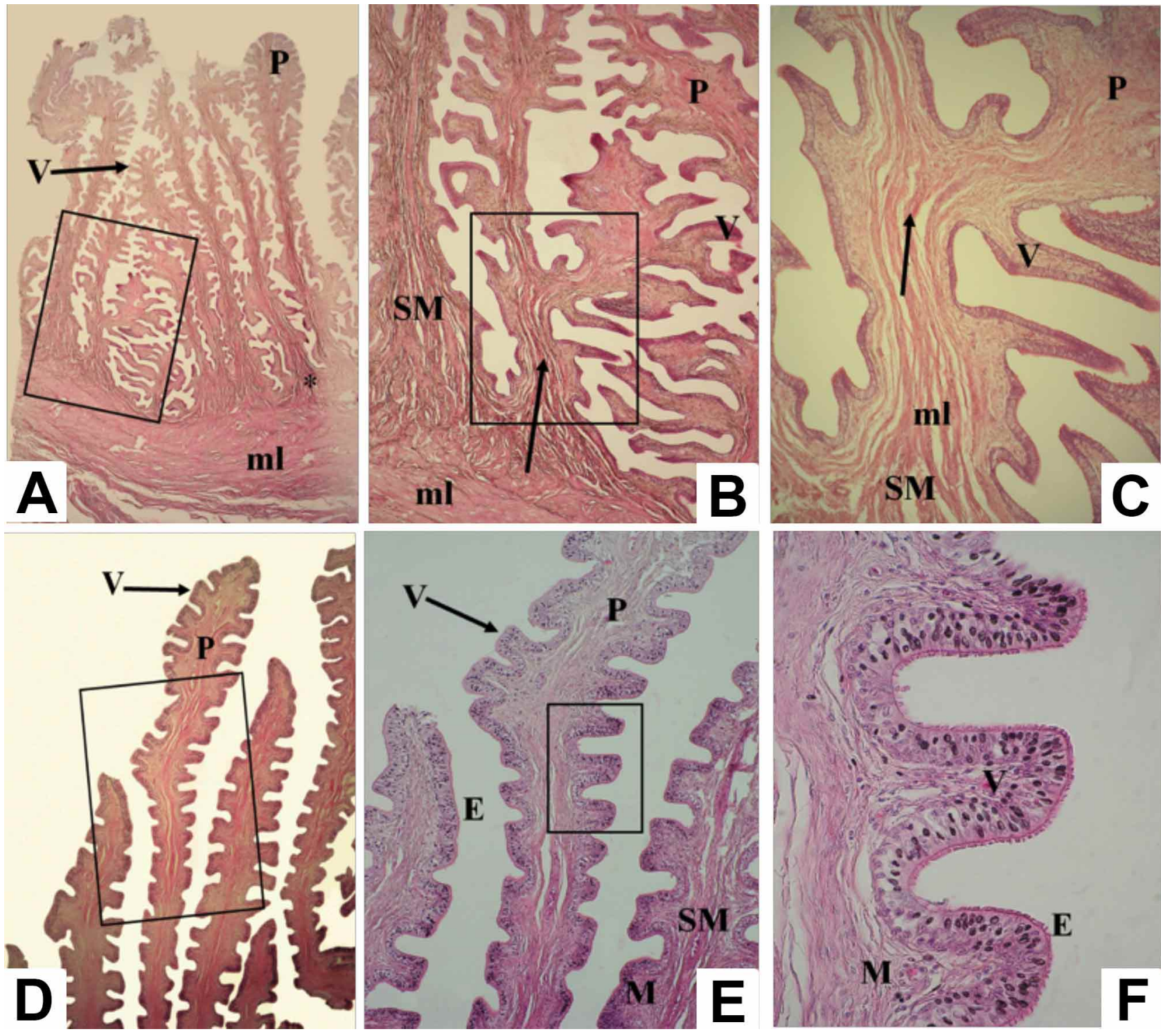

Fig. 7a: Corte histológico panorámico de pared de vagina con pliegues (P) largos, ramificados y con vellosidades (V). Musculatura lisa (ml) de disposición circular interna y plexiforme externa. La primera se proyecta en la submucosa (*) de los pliegues y sus ramificaciones. Tinción: HE, 12,5X. Fig. 7b: Mayor aumento del recuadro de la Fig. 7a. Muestra la musculatura lisa (ml) que se proyecta (flecha) en la submucosa (SM) de los pliegues (P) y ramificaciones. Vellosidades (V). Tinción: H-E, 100X. Fig. 7c: Mayor aumento del recuadro de la Fig. 7b. La musculatura lisa (ml) de la submucosa (SM) se proyecta en las ramificaciones (flecha) de los pliegues (P), y llega también a las vellosidades (V). H-E, 200X. Fig. 7d: Corte histológico de los pliegues (P) en su porción distal donde se observan las vellosidades (V). Tinción: H-E, 100X. Fig. 7e: Mayor aumento del recuadro de la Fig. 7d. Muestra el epitelio (E) de la mucosa (M) que recubre los pliegues (P) y sus vellosidades (V). Submucosa (SM). Tinción: H-E, 200X. Fig. 7f: Mayor aumento del recuadro de la Fig. 7e. Muestra la mucosa (M) con su epitelio de revestimiento seudoestratificado prismático ciliado con células caliciformes (E), que recubre las vellosidades (V). Tinción: H-E, 400X.

Desde el punto de vista histológico, la corteza ovárica del avestruz está cubierta por un epitelio de revestimiento que varía desde cúbico simple a prismático simple ciliado y también en sectores es prismático seudoestratificado, en cambio en la gallina es cúbico simple. Bajo el epitelio se encuentra una delgada capa de tejido conectivo denso constituyendo la túnica albugínea semejante a lo observado en la gallina (Fudge; Bacha \& Bacha, 2001). En el avestruz como ocurre en la ga- llina, los folículos se clasifican como primordiales, previtelogénicos, vitelogénicos y atrésicos. Éstos muestran una estructura microscópica similar a los de la gallina (Bacha \& Bacha; Kimaro, 2005). Sin embargo, en el avestruz los folículos en diferentes estados de desarrollo muestran miofibroblastos de disposición concéntrica (teca) que rodean la capa granulosa. Los miofibroblastos son muy notorios en la envoltura tecal de los folículos vitelogénicos. 
El oviducto es un largo conducto que macroscópicamente entre el avestruz y la gallina no muestran diferencias (Fudge; Bacha \& Bacha; Deeming; Hafez; Camiruaga). Sin embargo, a nivel microscópico la mucosa de los pliegues del infundíbulo, magnum, istmo, útero y vagina del avestruz está recubierta por un epitelio seudoestratificado prismático ciliado con células caliciformes. En la gallina es igual a excepción del infundíbulo que presenta un epitelio prismático simple ciliado (Bacha \& Bacha).

En cuanto al corion de la mucosa del oviducto en el avestruz también muestra diferencias, en el corion del infundibulum se observan glándulas alveolares y tubuloalveolares simples de secreción mucosa. Este tipo de glándulas se hallan también en abundancia en el corion de la mucosa esofágica y respiratoria de estas aves (Illanes et al., 2014). El corion del magnum presenta glándulas tubulares ramificadas de secreción serosa. El corion del istmo presenta glándulas tubulares simples de secreción serosa. El corion del útero presenta glándulas tubulares ramificadas de secreción serosa y el corion de la vagina carece de glándulas. En la gallina es semejante, sin embargo, el corion del infundíbulo no presenta glándulas y el de la vagina presenta glándulas tubulares simples de secreción serosa (Bacha \& Bacha). Éstas contribuirían a formar la cutícula de la cáscara del huevo (Fujii, 1963) y actúan como reservorio de espermatozoides (Bacha $\&$ Bacha; Hafez). En el avestruz es probable que el laberinto de pliegues, ramificaciones y vellosidades presente en la vagina actúe como reservorio de espermatozoides.

AGRADECIMIENTOS. A Frigoríficos Caren, por su cooperación, tanto con el material biológico como su disposición, sin ello no hubiera sido posible este análisis.

ILLANES, J.; MATUS, F.; LEYTON, V.; VENEGAS, F.; FERTILIO, B. \& CASTRO, M. Histological description of the ostrich female reproductive system (Strutio camelus var. Domesticus). Int. J. Morphol., 36(4):1252-1261, 2018.

SUMMARY: In the 1990's, ostrich production reached a peak in our country, boosted by the special characteristics of its meat and the potential of the derivatives. The breed raised is a hybrid called African Black (Struthio camelus var. domesticus) which has a high quality meat in terms of nutritional factors and flavor. With regard to reproduction, the female ostrich reaches maturity at the age of 2.5 years. Genital organs are very important in fowl's production, because they can generate fertility deficiencies that, in turn can diminish brood number. Histological analysis allows a better understanding of the basic structure of the female's genital organs and is a helpful tool to resolve breeding problems. For this analysis samples were obtained from the different segments of the reproductive system of 6 female ostrich in reproductive age. These samples were processed using standard histological technique. Sections were observed, photographed and analyzed under the light-microscope. Photographs were compared with hen's samples. The ostrich female's reproductive system has the particularity of having just the left ovary and oviduct developed. The ovary has a big size and a cluster shape which varies from season to season. It presents paramount, previtellogenic, vitellogenic and atresic follicles. The vitellogenic follicles have granulosa cells and inner and external theca. The oviduct presents cephalocaudally: infundibulum, magnum, isthmus, uterus and vagina, flowing into the urodeum. It shows long pleats of different length and number, with drusen of mucose and serose secretion, except in the vagina. The comparative histological analysis allowed us to establish that the basic structure of the female reproductive system is similar to that of the hen (Gallus gallus).

KEY WORDS: Ostrich; Histology; Female reproductive system.

\section{REFERENCIAS BIBLIOGRÁFICAS}

Bacha, W. J. \& Bacha, L. M. Atlas Color De Histología Veterinaria. $2^{\mathrm{a}}$ ed. Buenos Aires, Intermédica, 2001

Camiruaga, M. El Avestruz: Sistema de Producción en Chile. Santiago de Chile, Fundación para la Innovación Agraria, 2004.

Deeming, D. C. El Avestruz: Biología, Producción y Sanidad. Zaragoza, Acribia, 2001.

Dyce, K. M.; Sack, W. O. \& Wensing, C. J. G. Anatomia Veterinaria. $2^{\text {a }}$ ed. Ciudad de México, McGraw-Hill Interamericana, 2004.

Fudge, M. A. Laboratory Medicine Avian and Exotic Pets. California, Saunders, 2000.

Fujii, S. Histological and histochemical studies on the oviduct of the domestic fowl with special reference to the region of uterovaginal juncture. Arch. Histol. Jpn., 23:447-59, 1963.

Hafez, E. S. E. Reproducción e Inseminación Artificial en Animales. $7^{\mathrm{a}} \mathrm{ed}$. Ciudad de México, McGraw-Hill Interamericana, 2002.

Harrison, G. J. \& Lightfoot, T. L. Clinical Avian Medicine. Florida, Spix Publishing, 2005.

Huchzermeyer, F, W. Patología de Avestruces y otras Ratites. Madrid, Ediciones Mundi-Prensa, 2000.

Illanes, J.; Leichtle, J.; Leyton, V.; Tapia, L. F.; Fertilio, B. \& Castro, M. Histologic description of the different segments from the ostrich respiratory system (Struthio camelus var. domesticus). Int. J. Morphol., 32(4):1325-36, 2014.

Kimaro, W. H. An Immunohistochemical and Ultrastructural Study of the Ovary of the Immature Ostrich (Struthio camelus). M. Sc. Thesis. Pretoria, Department of Anatomy and Physiology, Faculty of Veterinary Science, University of Pretoria, 2005. Disponible en: https://repository.up.ac.za/ bitstream/handle/2263/23731/Complete.pdf?sequence=3

Luna, L. Manual of Histologic Staining Methods of the Armed Forces Institute of Pathology. $3^{\mathrm{a}}$ ed. New York, McGraw-Hill, 1968.

Sisson, S. \& Grossman, J. D. Anatomía de los Animales Domésticos.Tomo II. $5^{\text {a }}$ ed. Ciudad de México, Masson, 1999.

Whittow, G. C. Sturkies Avian Physiology. 5a ed. Hawaii, Academic Press, 2000.

Dirección para correspondencia:

Prof. Dr. Julio Illanes Herrero

Departamento de Morfología

Facultad de Medicina, Clínica Alemana

Universidad del desarrollo

Av. Las Condes 12.438, Lo Barnechea.

Santiago

CHILE

E-mail: jillanes@udd.cl

Recibido : 27-06-2018

Aceptado: 22-08-2018 